\title{
La gestión del sistema público de salud mediante compras de servicios al sector privado en Chile
}

\author{
Sebastián Flores DíAZ
}

\section{RESUMEN}

Este trabajo examina el uso de acuerdos bilaterales (contractuales y convencionales) para la provisión de prestaciones clínicas a los sistemas públicos de salud. La gestión contractual de la sanidad pública es un proceso común en las reformas sanitarias impulsadas desde la década de 1980, que pretendían transformar los sistemas sanitarios en mercados de servicios clínicos. Para tales propósitos, los contratos y convenios son los instrumentos jurídicos que utiliza el sistema público chileno para requerir las atenciones del sector privado. Sin embargo, la falta de un tratamiento sistemático de los contratos del Estado por parte del legislador provocó una discusión que terminó reduciendo todos los acuerdos a compras de servicios.

Palabras clave: servicios de salud, compras de prestaciones de servicios, contratación pública, convenios de colaboración.

1 Doctorando en derecho, Universidad Autónoma de Madrid, Madrid, España. Abogado y magíster en Derecho Público por la Universidad de Chile, Santiago, Chile. Correoe: sfloresabogado@gmail.com. Enlace ORCID: https://orcid.org/0000-0002-1829-2350. Fecha de recepción: 15 de enero de 2021. Fecha de modificación: 10 de abril de 2021. Fecha de aceptación: 10 de mayo de 2021. Para citar el artículo: Flores Díaz, Sebastián, "La gestión del sistema público de salud mediante compras de servicios al sector privado en Chile", Revista digital de Derecho Administrativo, Universidad Externado de Colombia, n. ${ }^{\circ}$ 26, 2021, pp. 163-196. DOI: https://doi.org/10.18601/21452946.n26.06. 


\title{
The Management of the Public Health System Through Purchases of Services Agreements with the Private Sector in Chile
}

\begin{abstract}
This paper examines the use of bilateral agreements (contractual and conventional) for the provision of clinical services to public health systems. Contractual management of public health care is a common process in the health reforms promoted since the 1980s, which aimed to transform health systems into markets for clinical services. For these purposes, contracts and agreements are the legal instruments used by the Chilean public system to require care from the private sector. However, the lack of a systematic treatment of public procurement by the legislator led to a discussion that ended up reducing all agreements to purchase of services agreements.

Keywords: Health services, Procurement of Services, Public Procurement, Collaboration Agreements.
\end{abstract}

\section{INTRODUCCIÓN}

La discusión en torno a la prestación de servicios médicos por parte del sector privado resurgió durante la pandemia del COVID-19, específicamente respecto de las potestades que la autoridad sanitaria podía ejercer sobre él. La búsqueda de un título de intervención que permitiera contar con la capacidad del sector privado para hacer frente a una demanda explosiva por los contagios que requirieran tratamientos clínicos, reflejó un problema complejo respecto de las prerrogativas con las que cuenta la autoridad sanitaria chilena para dirigir la prestación de atenciones clínicas por parte del sector privado.

La autoridad sanitaria chilena debió acudir a acuerdos bilaterales previamente celebrados con el sector privado para disponer de su capacidad y sortear los requerimientos que exigiera la pandemia. Los actos administrativos que se dictaron para requerir la cooperación de sector privado dan cuenta de esta circunstancia. En efecto, el artículo $2^{\circ}$ bis, del Decreto Supremo n. ${ }^{\circ} 4$ de 2020, del Ministerio de Salud de Chile ${ }^{2}$, otorgó potestades al subsecretario de Redes Asistenciales para que los establecimientos privados de 
salud facilitaran prestaciones asistenciales a precios previamente convenidos $^{3}$. Por su parte, el artículo $2^{\circ}$ de la Resolución Exenta n. ${ }^{\circ} 156$ de 2020 de la Subsecretaría de Redes Asistenciales ${ }^{4}$ definió a los prestadores privados como aquellos que tienen un convenio de colaboración o de otro tipo con la red pública de salud. Estos acuerdos remiten a las compras de servicios médicos privados, así como otros tipos contractuales ${ }^{5}$ para materializar un tipo colaboración público-privada.

Estas disposiciones dan cuenta de que la autoridad sanitaria chilena no dirigiría al sector privado, sino que compra sus servicios. Se señala que "compra" y no "contrata", pues ante la falta de una legislación general de contratos públicos ${ }^{6}$, se utiliza la Ley de Compras Públicas (Ley n. ${ }^{0} 19.886$, Ley de bases sobre contratos administrativos de suministro y prestación de servicios), que se refiere principalmente a suministros (contrato que a nivel comparado $^{7}$ y doctrinario ${ }^{8}$ se refiere a bienes) con la figura contractual de la prestación de servicios. En efecto, el artículo 2 de la Ley de Compras parece asimilar ambas figuras contractuales, y el reglamento de la ley es parco en cuanto a la regulación del contrato de prestación de servicios.

La ampliación del ámbito de aplicación de la Ley de Compras a los acuerdos entre entes del Sistema Nacional de Servicios de Salud (SNSS) con privados fue producto de la interpretación de la Contraloría General de la República

3 Artículo $2^{\circ}$ bis. "Otórgase a la Subsecretaría de Redes Asistenciales facultades extraordinarias para disponer, según proceda, de todas o algunas de las siguientes medidas: [...] 10. Coordinar la red asistencial del país, de prestadores públicos y privados. Para lo anterior, podrá solicitar de los establecimientos públicos y de los establecimientos privados, la facilitación, a los precios previamente convenidos, del otorgamiento de prestaciones asistenciales que no puedan postergarse sin grave perjuicio". Al respecto, Muñoz Machado explica que el precio es una retribución de un contratista que debe expresarse en la moneda de uso. Santiago Muñoz MACHADO, Diccionario panbispánico del español jurídico, Madrid: Santillana, 2017, p. 1555.

4 Este instrumento dispuso instrucciones para la coordinación de la red pública y privada de salud por parte de la subsecretaría de redes asistenciales.

5 MARISOl RodríGUEZ, "El sector público y el sector privado de la sanidad: cestabilidad

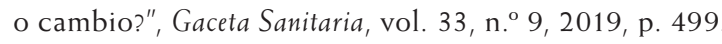

6 Gladys Camacho Cepeda, "Chile en la contratación pública en América Latina", en José Luis Benavides y Pablo Moreno Cruz (eds.), La contratación Pública en América Latina. Bogotá: Universidad Externado de Colombia, 2017, pp. 232-235; GLadys CamaCHO CePedA, "Certeza jurídica y el problema de la nulidad de los contratos públicos en Chile", Revista digital de Derecho Administrativo, n. ${ }^{\circ} 25,2020$, p. 146.

7 Cfr. artículo 2.8 de la Directiva 2014/24/UE, o el artículo 16 de la Ley 9/2017 de España, Ley de Contratos del Sector Público.

8 Santiago Muñoz MaChado, Diccionario panbispánico del español jurídico, p. 624; SANTIAGO MuÑOZ MACHADO, Tratado de derecho administrativo y derecho público general. XIII contratos del sector público, Madrid: Agencia Estatal Boletín Oficial del Estado, 2018, pp. 114-115. 
(en adelante, Contraloría) ${ }^{9}$, que considera cualquier acuerdo oneroso ${ }^{10}$ entre entes administrativos con particulares se rige por la aludida ley. Además, indica que este cuerpo legal sería una ley de bases ${ }^{11}$.

La decisión de la Contraloría pretendía que los acuerdos bilaterales cumplieran con los principios de probidad y transparencia, así como el buen uso de los recursos públicos ${ }^{12}$. Posteriormente, la Contraloría indicó que mediante estos acuerdos existía un traspaso de funciones públicas ${ }^{13}$.

Sin embargo, este último aspecto fue controvertido por el Tribunal Constitucional, que en su sentencia de 18 de enero de $2019^{[14]}$ se pronunció sobre la naturaleza de los convenios regulados por el DFL 36/80 (Decreto con Fuerza de Ley n. ${ }^{\circ} 36$ de 1980, del Ministerio de Salud). En el considerando $18^{\circ}$ indicó lo siguiente:

De suerte que, ante la imposibilidad del Estado de asumir la gestión de todas aquellas funciones que [los cuerpos intermedios] venían satisfaciendo con anterioridad y de otras que aparecen con la revolución industrial, la llamada Escuela de Burdeos, de inicios del siglo XX, junto con asignarles el rótulo de "servicio público" a dichas actividades, articula la figura de la "concesión de servicio público", como un contrato que permite al Estado "delegar" en los privados su llevanza. Sin menoscabo de la facultad del Estado para disciplinar esa actividad y para rescatar su titularidad.

Supuestos que, como es posible advertir, no son del todo compatibles con el derecho público chileno, que parte por el deber del Estado de reconocer y amparar a los cuerpos intermedios de la sociedad, garantiza ampliamente la libertad de asociación, y permite iure proprio a las instituciones privadas participar en el quehacer de la salud.

El Tribunal Constitucional añade que en los acuerdos bilaterales del SNSS no hay una delegación de tareas públicas, sino que se trata de un acuerdo para que el sector privado brinde prestaciones específicas al sistema público, como compras de atenciones en las que la Administración no tiene poderes de dirección ni control.

9 Una explicación sobre la naturaleza y labor que desempeña la Contraloría General de la República en el sistema chileno se encuentra en Francisco Velasco Caballero, Administraciones públicas y derechos administrativos, Madrid: Marcial Pons, 2020, pp. 98-99.

10 Dictámenes n. ${ }^{\circ} 51.081$ de 2006 y n. ${ }^{\circ} 38.109$ de 2007.

11 Nancy Barra Gallardo y Gabriel Celis Danzinger, Contratación administrativa bajo la ley de compras, 4. ${ }^{a}$ ed., Santiago: Thomson Reuters, 2015, p. 16.

12 Sebastián Flores Díaz, "La participación privada en la gestión de la salud pública", Revista de Gestión Pública", vol. IX, n. ${ }^{\circ} 1,2021$, p. 64.

13 Dictamen n. ${ }^{\circ} 44.822$ de 2011.

14 Tribunal Constitucional, sentencia de 18 de enero de 2019 , roles n. ${ }^{\circ}$ 5.572-2018 y $5.650-2018$ 
Desde un punto de vista sistemático, los acuerdos bilaterales entre entes del SNSS y particulares corresponde a una actividad contractual de la Administración. Se trata de acuerdos para la gestión de servicios públicos que van más allá de la simple provisión de bienes ${ }^{15}$. Sin embargo, el problema está en la ambigüedad legislativa respecto de los convenios administrativos y contratos públicos en el ámbito de la gestión sanitaria. El legislador autoriza a diferentes entes a celebrar convenios y contratos, pero no da definiciones de ninguno de los dos conceptos, ni tampoco contempla reglas para todos los casos. Especialmente, los convenios que los entes del SNSS celebran con particulares no se contemplan como posibilidad en la LOCBGAE (Ley n. ${ }^{\circ} 18.575$, Ley Orgánica Constitucional de Bases Generales de la Administración del Estado) que solo autoriza los convenios interadministrativos. Camacho señala que el legislador chileno es reticente a implementar normativas sobre contratos estatales, y los operadores jurídicos han tratado de construir principios y reglas generales de leyes especiales ${ }^{16}$, como la Ley de Compras Públicas.

Por otro lado, la vis expansiva de la Ley de Compras Públicas pareciera que induce a más confusiones que soluciones. Se trata de un cuerpo legal que, si bien menciona que es aplicable en la contratación de servicios, se refiere casi exclusivamente a la provisión de suministros.

La hipótesis de trabajo se refiere a la naturaleza que tienen los acuerdos contractuales entre el SNSS y los particulares, si se trata de contratos para mejorar la competencia en un mercado de prestaciones sanitarias ${ }^{17}$ o si se trata de acuerdos para colaborar con el sistema. Las consecuencias prácticas de esta distinción son claras, pues no es lo mismo que un prestador privado se asocie a la red asistencial para otorgar camas críticas (lo que implica personal especializado e infraestructura) que comprar bisturís u otros insumos médicos. En el primer caso, la Administración cumple un rol de garante de un derecho fundamental, mientras que en el segundo hay un propósito económico, que no necesariamente subordina al primero.

Asimismo, es necesario tener presente que en los últimos proyectos de ley presentados en el periodo 2018-2021, el poder político pretende eliminar los convenios del SNSS, en lugar de regularlos y mejorarlos, para reemplazarlos por una aplicación generalizada de la Ley de Compras Públicas.

15 Juan Carlos Cassagne, "Actuales desafíos y clásicos dilemas de la contratación pública", en José Carlos Laguna de Paz, Íñigo Sanz Rubiales e Isabel de los Mozos Touya (coords.), Derecho administrativo e integración europea. Estudios en bomenaje al profesor José Luis Martínez López-Muñiz, Madrid: Reus, 2017, p. 982.

16 Gladys Camacho Cepeda, "Certeza jurídica y el problema de la nulidad de los contratos públicos en Chile", Revista digital de Derecho Administrativo, 2021, n. ${ }^{\circ} 25$, p. 146.

17 Véase Sebastián Flores Díaz, "La participación privada en la gestión de la salud pública", p. 55 . 
En el presente trabajo se aborda la contractualización de la gestión sanitaria desde un punto de vista económico y su repercusión en el derecho administrativo (1); posteriormente se mencionan las reformas y modificaciones legales al sistema de salud chileno como casos en los que se ha tendido a la contractualización de las relaciones entre entes públicos y proveedores de servicios (2); y finalmente se aborda la distinción entre convenios, contratos y compras (3).

\section{LA CONTRACTUALIZACIÓN DE LA GESTIÓN SANITARIA SALUD}

La contractualización designa la extensión objetiva de las técnicas del contrato en todo tipo de relaciones ${ }^{18}$. En el ámbito del derecho administrativo, se trata de práctica administrativa, así como una tendencia y también una idea (o ideología $)^{19}$. La idea sería el abandono de mecanismos iusadministrativos de actuación por formas e instrumentos del derecho privado ${ }^{20}$. También está la idea de la externalización en la prestación de servicios públicos ${ }^{21}$ (el contracting out). Hay un fuerte componente ideológico en este último aspecto, en el que las prestaciones importantes son encomendadas al mercado y la Administración renuncia a regularlas, en el entendido que la sociedad será la que regulará22. Como indica Schmidt-Assmann, la contractualización no es un medio inofensivo de la Administración ${ }^{23}$.

Por su parte, existe una tendencia de usar mecanismos contractuales para acudir a la cooperación con particulares, cuestión que no es nueva ${ }^{24}$. Pero los procesos de reforma administrativa, basados en la liberalización, privatización,

18 Alain SUPIOT, Homo juridicus. Ensayo sobre la función antropológica del derecho, 2. ed., Buenos Aires: Siglo Veintiuno Editores, 2012, p. 128.

19 Eberhard SCHMidT-AssmanN, "Contractualización del derecho administrativo", en Alberto Montaña Plata y Jorge Rincón Córdoba, Contratos públicos: Problemas, perspectivas y prospectivas, Bogotá: Universidad Externado de Colombia, 2017, p. 736.

20 Mercé DaRnaculleta I GaRdella, Derecho administrativo y autorregulación: La autorregulación regulada, tesis doctoral, Girona: Universitat de Girona, 2002, p. 62; JosÉ Esteve PARDO, "La deconstrucción de las fórmulas de intervención administrativa. De la aplicación de la Ley a la contractualización", Revista Vasca de Administración Pública, 2014, n. ${ }^{\circ}$ 99-100, pp. 1231-1239.

21 Margarita Cárdenas Poveda, "La armonización del derecho administrativo en la Globalización", en John Tito Añamuro (dir.), Derecho internacional privado. Un estudio de tratados, proyectos de unificación y leyes modelos, Barranquilla: Universidad del Norte, 2020, p. 210.

22 Eberhard SCHMidT-ASSMANN, "Contractualización del derecho administrativo", p. 724.

23 Ibid., p. 719.

24 Ibid., p. 721. 
desregulación y el New Public Management aceleraron la tendencia ${ }^{25}$. Aunque desde la gobernanza también se impulsa la colaboración de particulares en la gestión de servicios públicos, así como en la definición de políticas públicas y de decisiones administrativas ${ }^{26}$.

En el campo de la prestación de servicios de salud, la tendencia de contractualizar las relaciones entre el Estado (o el responsable del financiamiento) con los proveedores de servicios tiene su origen claro en la década de 1990. Los antecedentes directos son dos informes del Banco Mundial de 1987 y de 1993. El primero propone descentralizar los sistemas sanitarios estatales para reducir la deuda pública. El segundo, titulado "Invertir en salud", mantiene la recomendación de descentralizar los sistemas estatales, pero añade que es necesario que el sector público contrate con los privados para que ellos realicen las prestaciones de salud. La Organización Mundial de la Salud (OMS) en 2000 se sumó a estas propuestas ${ }^{27}$.

\subsection{LAS REFORMAS A LA SALUD COMO ANTECEDENTE DE LA CONTRACTUALIZACIÓN DE LA GESTIÓN}

Los mecanismos contractuales en la provisión de prestaciones médicas es una tendencia global que ha inspirado la gran mayoría de las reformas a los sistemas sanitarios desde la década de 1980 en adelante ${ }^{28}$. Se denomina convergencia impulsada por el mercado ya que tiene por objeto crear condiciones de mercado en los sistemas sanitarios ${ }^{29}$. También se conocieron como reformas neoliberales ${ }^{30}$. El proceso fue convergente pues, con independencia del modelo y sistema sanitario de cada país, las reformas apuntaron en la misma dirección, y con medidas similares.

Estas reformas tuvieron como modelo de inspiración las reformas al National Health Service británico que pretendieron crear condiciones de

25 Ibid., p. 722.

26 Francisco Velasco Caballero, Administraciones públicas y derechos administrativos, pp. 96-97.

27 Organización Mundial De La Salud, Informe sobre la salud en el mundo 2000. Mejorando el desempeño de los sistemas de salud, Ginebra: Organización Mundial de la Salud, 2000, p. 78 .

28 José Repullo Labrador, "Sistemas Sanitarios y reformas: dimensiones, escenarios y patrones", en Gestión sanitaria para la calidad y la excelencia, Madrid: José Repullo Labrador, 2014, pp. 56-62.

29 Nathan Cortez, "Globalization", en I. Glenn Cohen, Allison Hoffman, William M. Sage y Kathleen G. Sebelius (eds.), The Oxford Handbook of U.S. Health Law, Oxford: Oxford University Press, 2015, p. 1077.

30 Solomon Benatar, David Sanders y Stephen Gill, "The Global Politics of Healthcare Reform", en Colin Mcinnes, Kelley Lee y Jeremy Youde (eds.), The Oxford Handbook of Global Health Politics Oxford: Oxford University Press, 2018, pp. 445-468 
mercado en la prestación de servicios ${ }^{31}$. Este proceso impulsado desde organismos internacionales de crédito ${ }^{32}$ tuvo, entre otros, dos aspectos relevantes para este trabajo: el pago de los servicios concebido como una "compra" y la contratación de prestaciones a proveedores privados. Ambos son conceptos jurídicos que utilizados desde la economía tuvieron un alcance diferente. La función de compra de servicios se refiere al financiamiento del sistema de salud, mientras que la contratación de prestaciones se refiere a la forma de gestión, en una lógica de transformar los servicios médicos en un mercado de servicios en el que el ciudadano se transforma en un consumidor de atenciones de salud.

La compra es definida como la selección y el pago de los distintos proveedores $^{33}$, o "el pago de dinero proveniente del fondo común a los prestadores de salud para que entreguen un conjunto (no necesariamente específico) de servicios de salud" ${ }^{\prime \prime}$, que puede ser pública, si es realizada por un ente público (como el Fonasa o los Servicios de Salud en el caso chileno) o privada (si es realizada por una aseguradora privada o directamente por el usuario). La compra se enmarca en la concepción contractualista de la teoría de la agencia, que entiende los contratos como incentivos que alinean los intereses entre los distintos actores ${ }^{35}$. Esta teoría señala que, en el caso de los sistemas de salud, el Estado, mediante un contrato, delega el desempeño de un servicio a una organización para que brinde las prestaciones de salud ${ }^{36}$.

31 Jonathan Filippon et al., "A 'liberalização' do Serviço Nacional de Saúde da Inglaterra: trajetória e riscos para o direito à saúde", Cadernos de Saúde Pública, vol. 32, n. . 8, 2016; Marcos Vergara, "Reforma de los Mecanismos de Pago del Sector Público de la Salud en Chile", 2020. Recuperado de https://www.uchile.cl/noticias/144204/reformade-los-mecanismos-de-pago-del-sector-publico-de-la-salud [consultado el 12 de enero de 2021].

32 Solomon Benatar et al., "The Global Politics of Healthcare Reform"; Carlos Barba SOLANO, "Liberalismo y universalismo: 25 años de reformas sociales en los regímenes de bienestar de América Latina", en Carmen Midaglia, Gerardo Ordóñez y Enrique Valencia (eds.). Políticas sociales en América Latina en los inicios del siglo XXI. Innovaciones, inercias y retrocesos, Buenos Aires: Clacso, 2018, pp. 75-108.

33 Jordi Sevilla e Ignacio Riesgo, Qué está pasando con tu sanidad, Barcelona: Profit Editorial, 2018, p. 78.

34 Marcos Vergara y María Soledad Martínez, "Financiamiento del sistema de salud chileno", Salud pública de México, vol. 48, n. ${ }^{\circ}$ 6, 2006, pp. 512-521.

35 DANiel MaCeIRA, Mecanismos de pago a prestadores en el sistema de salud: Incentivos, resultados e impacto organizacional en países en desarrollo. Estudios Mayores de Investigación Aplicada 2, Documento de Trabajo 2, Bethesda: Partnerships for Health Reform Project, Abt Associates Inc., 1998, pp. $3-4$.

36 Álvaro Franco-Giraldo, "Sistemas de salud en condiciones de mercado: las reformas del último cuarto de siglo", Revista Facultad Nacional de Salud Pública, vol. 32, n. ${ }^{\circ}$ 1, 2014, pp. 98-107. 
Por su parte, la contratación de prestaciones a particulares se enmarca en un proceso paralelo, conocido como contractualización en salud, que se refiere a una modernización de la gestión que para mejorar el rendimiento y la rendición de cuentas de los proveedores de salud ${ }^{37}$. Este proceso es parte de la nueva gestión pública (New Public Management) en que se engloba las colaboraciones público-privadas, así como el uso de contratos y una orientación hacia el mercado, entre otras características ${ }^{38}$. Se trata en último término del uso de formas privadas de gestión ${ }^{39}$.

Ambos aspectos, función de compra y contratación de servicios, están dirigidos a rediseñar la actuación del Estado en la salud. La compra tiene por objeto que el Estado solo pague la atención de salud y no la burocracia asociada a la gestión de la institución, y la contratación está enmarcada en el proceso de externalización de los servicios.

Desde la década de 2000 la Organización Mundial de la Salud (OMS) impulsó el uso de mecanismos contractuales en la gestión de prestaciones de salud ${ }^{40}$. En el Informe sobre la salud en el mundo de 2000, la OMS crítica a los sistemas de salud organizados de forma burocrática jerárquica ${ }^{41}$ y recomienda la organización del sistema de salud por medio de acuerdos contractuales de largo plazo que dejen en manos del Estado la dirección de la política sanitaria ${ }^{42}$

El Consejo Ejecutivo de la OMS propuso en 2001 avanzar en los arreglos contractuales, que clasificó en tres grupos ${ }^{43}$ :

- La delegación de responsabilidad: se trataría de una especie de concesión de servicio público.

- La compra de servicios: se acude al mercado para comprar diferentes prestaciones, que inicialmente consistían en actividades no médicas, pero

37 Maria Albuquerque, Heloísa Morais y LuCi Lima, "Contratualização em saúde: arena de disputa entre interesses públicos e privados", Ciência \& saúde coletiva, vol. 20, n. ${ }^{\circ}$ 6, 2015, pp. 1825-1834.

38 Marjorie Morales-Casetti, Marco Bustos-Gutiérrez y Jenny Cerda-Bustos, "Efectos de la nueva gestión pública en el desempeño: Análisis de los hospitales públicos chilenos", Revista de Salud Pública, vol. 21, n. ${ }^{\circ} 3,2019$, pp. 1-7.

39 Francisco Velasco Caballero, "Reformas de la Administración pública: Fenomenología, vectores de cambio y función directiva del derecho administrativo", Anuario de la Facultad de Derecho de la Universidad Autónoma de Madrid, n. ${ }^{\circ} 23,2019$, p. 112.

40 Marcos Vergara y María Soledad Martínez, "Financiamiento del sistema de salud chileno", pp. 512-521.

41 Organización Mundial de la SAlud, Informe sobre la salud en el mundo 2000, p. 70.

42 Ibid., p. 71.

43 Organización Mundial de la Salud, 109.a reunión del Consejo Ejecutivo. Función de los arreglos contractuales en la mejora del desempeño de los sistemas de salud, Ginebra: Organización Mundial de la Salud, 2001. 
que, con el avance de la contractualización, se volvió en un mecanismo para la realización de actividades sanitarias.

- La cooperación: se caracterizan por las posibilidades de sinergia entre el sector público y los privados que colaboran en un objetivo común.

Estas reformas transformaron a los entes públicos responsables de garantizar la provisión de servicios de salud en brokers de esos servicios, redefiniendo a los usuarios como consumidores.

\subsection{LOS MECANISMOS CONTRACTUALES ANTE EL DERECHO ADMINISTRATIVO}

El análisis del derecho administrativo por sí solo no entrega explicaciones para los procesos de evolución y mutación de la Administración acudir a otras disciplinas ${ }^{44}$. En este sentido, es importante considerar los efectos que ha tenido la nueva gestión pública en la proliferación de mecanismos contractuales en las relaciones de la Administración con los particulares ${ }^{45}$.

La nueva gestión pública propone la contractualización como herramienta para la provisión de servicios que eran brindados por entidades o funcionarios públicos ${ }^{46}$. Para este paradigma, contractualización es sinónimo de externalización de servicios ${ }^{47}$.

El concepto de externalización es ajeno a la doctrina jurídica lo que produce algunos inconvenientes ${ }^{48}$. No se trata de un abandono de una actividad por parte de la Administración sino de una gestión de la misma por parte de privados ${ }^{49}$. El fenómeno de la externalización conduce a la contratación pública $^{50}$, y en una forma más genérica a la colaboración público-privada.

Hay una fuerte controversia política respecto del uso de contratos administrativos para la gestión de la sanidad, pues se ve como una privatización

44 Francisco Velasco Caballero, "Reformas de la Administración pública". p. 111.

45 Eberhard Schmidt-ASSMAnN, "Contractualización del derecho administrativo", p. 722.

46 Cristián Pliscoff-Varas, "Implementando la nueva gestión pública: Problemas y desafíos a la ética pública. El caso chileno", Convergencia, vol. 24, n. ${ }^{\circ} 73,2017$, p. 150.

47 Ibid., p. 145

48 Josefa Cantero Martínez, "La incidencia del fenómeno de la externalización en la Administración General del Estado. ¿Existe algún límite?", Documentación Administrativa, n. ${ }^{\circ} 286-287,2010$, p. 298.

49 Juan Gorelli Hernández, "La externalización de los servicios sanitarios públicos y las posibles consecuencias laborales", en Federico Castillo Blanco (dir.), Público y privado en la gestión de los servicios públicos: Reestructuración, externalización y reversión a la Administración [ePub], Madrid: INAP, 2019, pp. 177-206.

50 Josefa Cantero Martínez, "La incidencia del fenómeno de la externalización en la Administración General del Estado", p. 304. 
encubierta ${ }^{51}$. Ahora bien, es necesario consignar que la gran mayoría de los países admite diversos grados de colaboración público-privada en los sistemas de salud ${ }^{52}$, pues los particulares también son actores relevantes en la protección y recuperación de salud, y su actividad se realiza de forma paralela al Estado ${ }^{53}$. Además, la distinción entre lo público y lo privado en la atención sanitaria no es clara en la mayoría de los países ${ }^{54}$.

Con independencia de la consagración constitucional del derecho de protección de la salud (en su vertiente individual como derecho a la asistencia sanitaria), la mayoría de los Estados asumen la responsabilidad de prestar directamente o financiar las atenciones sanitarias, así como de regular la forma en que el sector privado participará en los sistemas de la salud ${ }^{55}$. En el primer caso, el Estado puede definir su actividad en materia sanitaria como una prestación directa por parte de los entes dependientes de la sanidad pública o como aseguramiento público derivado de la seguridad social o como una combinación de ambos ${ }^{56}$. En el segundo caso, el Estado establece las normas en que los privados deben prestar estas atenciones de salud. En consecuencia, por diferentes razones, los Estados asumen un compromiso en las prestaciones de salud.

\section{LAS REFORMAS CHILENAS EN SALUD COMO ANTECEDENTE DE LA GESTIÓN VÍA COMPRAS}

La discusión política sobre el uso de mecanismos contractuales en la sanidad repercute en el derecho administrativo, que, como indica Velasco Caballero, es político y tendencialmente arbitrario, pues responde a aspiraciones

51 Tomás Font i Llovet, "Organización y gestión de los servicios de salud: El impacto del derecho de la Unión Europea", en Vera Parisio, Vincent Aguado y Cudola y Belén Noguera de la Muela (eds.), Servicios de interés general colaboración público-privada y sectores específicos", Valencia: Tirant Lo Blanch, 2016, p. 201.

52 Nathan Cortez, "Globalization", pp. 1077-1078; Ricard Meneu y Rosa Urbanos, "La colaboración público-privada en sanidad. Hasta dónde y cómo delimitar sus fronteras", Cuadernos Económicos del ICE, n. ${ }^{\circ}$ 96, 2018, p. 41.

53 José Vida Fernández, "Los servicios públicos de solidaridad en la Unión Europea: Los límites del mercado único y la competencia en los servicios de interés general", en Tomás de la Quadra-Salcedo (ed.), Los servicios públicos tras la crisis económica: en especial la asistencia sanitaria en la Unión Europea, Valencia: Tirant Lo Blanch, 2017, p. 44.

54 Nathan Cortez, "Globalization", pp. 1077-1078.

55 Lawrence Gostin y Phil Fennell, "Health: The Health Care System, Therapeutic Relationships, and Public Health", en Mark Tushnet y Peter Cane (eds.), The Oxford Handbook of Legal Studies, Londres: Oxford University Press, 2005, p. 435.

56 Juan Bestard Perello, "Servicio público versus aseguramiento público. Apuntes ante retos pendientes (II)", Actualidad del Derecho Sanitario, n. ${ }^{\circ} 272,2019$, p. 695. 
del electorado en un momento concreto, lo que lo lleva a ser parcialmente obsoleto y contradictorio ${ }^{57}$. Esto resalta en las reformas a la salud realizadas en Chile. La impulsada por el régimen militar pretendía liberalizar las prestaciones sanitarias y construir un mercado sanitario, cuestión que quedó frustrada por la recesión económica de 1982. También está la modificación legal de la Ley n. ${ }^{\circ} 19.650$ y la reforma AUGE/GES ${ }^{58}$ de la década de 2000. Cada de una de ellas otorgó atribuciones para celebrar acuerdos bilaterales con el sector privado:

- La reforma del régimen autoritario, que mediante el DL 2.763/79 (Decreto Ley n. ${ }^{\circ} 2.763$, de 1979, que reorganiza el Ministerio de Salud y crea los Servicios de Salud, el Fondo Nacional de Salud, el Instituto de Salud Pública de Chile y la Central de Abastecimiento del Sistema Nacional de Servicios de Salud), otorgó atribuciones a los directores de los servicios regionales de salud para celebrar convenios, regulados en el DFL 36/80. Posteriormente, estableció que el Fonasa (Fondo Nacional de Salud) podía celebrar acuerdos con particulares para que estos se incorporaran en la modalidad de libre elección.

- La Ley n. ${ }^{\circ} 19.650$ de 1999, conocida como Ley de Urgencias o Ley de la Compra Publica, que facultó a Fonasa a celebrar convenios con particulares para incorporarse en su modalidad de atención institucional.

- La reforma AUGE/GES del periodo 2002-2005, que a través de la Ley n. ${ }^{\circ}$ 19.937, facultó a los directores de los hospitales (denominados Establecimientos Autogestionados en Red) para celebrar convenios y contratos de compra de servicios.

Tanto las dos reformas, como la modificación legal de 1999, tienen en común una tendencia a la externalización de las prestaciones de salud, junto con su ambigüedad en el tratamiento de los acuerdos bilaterales con particulares. En ellas, la técnica legislativa fue la autorización a Fonasa y los prestadores

57 Francisco Velasco Caballero. "Ideas ordenadoras del derecho administrativo", en Marcos Vaquer Caballería, Ángel Manuel Moreno Molina y Antonio Descalzo González (Coords.), Estudios de derecho público en bomenaje a Luciano Parejo Alfonso, Valencia: Tirant Lo Blach, 2019, p. 1209.

58 Durante el gobierno de Ricardo Lagos (2000-2006) se reformó el sistema de salud mediante la ampliación de la cobertura y el aseguramiento de determinados derechos. Inicialmente se denominó Plan Auge (Acceso Universal con Garantías Explícitas) para denominar al núcleo conceptual de la futura reforma. Véase VICENTE VALDIVIESO y JOAQuín MOnTERO, "El Plan auge: 2005 a 2009", Revista Médica de Chile, vol. 138, n. o 8, 2010 pp. 1040-1046. La discusión política y las tensiones que se generaron con los gremios de la salud obligó a cambiarle el nombre a la reforma que se denominó Garantías Explícitas en Salud (GES), las que se reconocieron en Ley n. ${ }^{\circ}$ 19.966. Aunque el gobierno de Lagos y el de su sucesora, Michelle Bachelet, se refirieron a la reforma como GES, esta se conoció como la reforma Auge, y con posterioridad se le denominó AUGE/GES. 
públicos -los Servicios (Regionales) de Salud-para celebrar "convenios" con el sector privado.

Aunque en el diseño inicial, la reforma del régimen militar no autorizó a Fonasa a celebrar convenios. Recién 1985, mediante la Ley n. ${ }^{\circ} 18.469$, se le facultó para celebrar acuerdos con particulares que quisieran incorporarse en la modalidad de libre elección, una especie de concierto ${ }^{59}$ o actividad concertada. La modificación legal de la Ley n. ${ }^{\circ} 19.650$ permitió a Fonasa celebrar convenios con particulares para incorporarlos en la modalidad de atención institucional. Pero no se establecieron los procedimientos para celebrar dichos acuerdos.

A continuación, se hace una breve exposición de las reformas sanitarias en Chile.

\subsection{LA REFORMA DEL RÉGIMEN MILITAR}

La reforma de 1979 fue un proceso que desmanteló el Sistema Nacional de Salud que teóricamente pretendió imitar al National Health Service británico ${ }^{60}$, y separó las funciones de regulación, prestación y financiamiento. Este proceso es parte de las reformas estructurales conocidas como "las siete modernizaciones" relativas a:

- El plan laboral, relativo a la desregulación del trabajo y la organización sindical.

- Reforma de la previsión, estableciendo un sistema de capitalización individual.

- Directiva sobre educación, cuyo objeto fue municipalizar la educación pública.

59 Dentro de las fórmulas contractuales con las que cuenta la Administración para requerir la colaboración del sector privado está el concierto. Se trata de un "contrato administrativo en el que un particular utiliza sus propias instalaciones para atender a los usuarios, y asume la prestación de un servicio a cambio de recibir de la Administración una remuneración económica por cuenta fija", DAVID BLANQUER CRIADO, La concesión de servicio público, Valencia: Tirant Lo Blanch, 2012, p. 413. En el ordenamiento jurídico español, se contempla expresamente la existencia del concierto sanitario (artículo 90 de la Ley 14/1986, General de Sanidad).

60 Durante la vigencia de la Constitución de 1925 coexistieron dos sistemas de salud. El Servicio Médico Nacional de Empleados (Sermena) y el Servicio Nacional de Salud. La diferencia entre uno y otro eran los beneficiarios, basada en la distinción que hacía el artículo $2^{\circ}$ del Código del Trabajo de 1931, que distinguía entre empleados (cuyo trabajo predomine el esfuerzo intelectual sobre el físico) y obreros (por cuenta ajena en un oficio u obra de mano o preste un servicio material determinado). Véase MARIO Parada-LezCano y Fabián MORAGa-Cortés. "Crise do seguro saúde no chile: doença crônica socialmente transmissível", Tempus, actas de saúde colet, vol. 1, n. ${ }^{\circ}$ 2, 2019, p. 181. 
- Reforma al sistema judicial.

- La reforma agrícola, con el objeto de revertir en parte la reforma agraria.

- La reforma a la administración del Estado, conocida como regionalización.

- La reestructuración del sistema de salud.

Uno de los arquitectos de esta reforma fue el entonces ministro del trabajo José Piñera Echeñique, quien señaló que no era competencia del Estado producir las prestaciones de salud, sino obtener los recursos necesarios para subsidiar a quienes tienen los menores ingresos. La provisión de servicios de salud debería hacerla la empresa privada en un contexto de competencia ${ }^{61}$. En este mismo sentido, el general Pinochet, en su mensaje del 11 de septiembre de 1980, indicó que los tres objetivos de la reforma a la salud pública eran: la focalización de la actuación estatal en quienes no podían pagar por prestaciones de salud, permitir la libre elección del prestador por parte de los beneficiarios del Sistema de Salud, y racionalizar el funcionamiento del aparato público en salud, minimizando los costos de su funcionamiento ${ }^{62}$ (reducción de personal).

Se pretendía realzar el principio de subsidiariedad del Estado garantizando la libre concurrencia del sector privado en la prestación de servicios médicos ${ }^{63}$.

El artículo $3^{\text {o[64] }}$ del DL 2.763/79 autorizó a los Servicios (Regionales) de Salud para celebrar convenios con entes privados para que estos se adscribieran al sistema, y el artículo 20. i $^{[65]}$ facultó a los directores de dichas

61 José PIÑERA ECHEÑIQUe, Informe económico. 1976-1977. Santiago: edición propia, 1977, p. 39.

62 Biblioteca del Congreso NaCiOnal, Mensaje presidencial. 11 septiembre 1979-11 septiembre 1980, Santiago: Biblioteca del Congreso Nacional, 1980, p. 7.

63 Biblioteca del Congreso Nacional, Historia del Decreto Ley n. ${ }^{2} .763$, Santiago: Biblioteca del Congreso Nacional, 1979, pp. 9-10.

64 Artículo 3: "Las personas, instituciones y demás entidades privadas, gozarán de libre iniciativa para realizar acciones de salud, en la forma y condiciones que determine la ley, así como para adscribirse al sistema, suscribiendo con los organismos que lo integran los convenios que corresponda".

65 Artículo 20: Para el desempeño de sus funciones el Director tendrá las siguientes atribuciones: i) Celebrar, también, con autorización del Ministerio de Salud y en conformidad con lo dispuesto en el artículo $9^{\circ}$ transitorio de este decreto ley, convenios con universidades, organismos, sindicatos, asociaciones patronales o de trabajadores y, en general, con toda clase de personas naturales o jurídicas, a fin de que tomen a su cargo, por cuenta del Servicio, algunas acciones de salud que a este correspondan por la vía de la delegación o de otras modalidades de gestión, previa calificación de la suficiencia técnica para realizar dichas acciones. Los Servicios podrán pagar las prestaciones en 
unidades a celebrar los convenios. Por su parte, el artículo 9 transitorio ${ }^{66}$ facultó al presidente de la República a dictar un decreto con fuerza de ley que regulara la celebración de estos convenios con entes no estatales. La regulación legal contiene ciertas particularidades:

- El artículo $3^{\circ}$ utiliza el concepto de adscripción al sistema para diferenciarlo de la incorporación. Durante la discusión del proyecto de decreto se consideró que la incorporación implicaba un vínculo de subordinación del ente privado hacia el servicio de salud, por lo tanto, se utilizó el concepto de adscripción deliberadamente para indicar que los privados colaboran en un plano de igualdad ${ }^{67}$.

- El artículo 20.i, inciso primero, establece que estos convenios son una delegación de gestión. Vale decir, se trata de una cesión puntual de competencias a una entidad privada, pero se mantiene el control por parte del Servicio de Salud y del Ministerio (inciso tercero). Complementa esta idea el artículo $9^{\circ}$ transitorio, que indica que las personas naturales o jurídicas que celebren estos convenios tomarán por cuenta del respectivo de Servicio de Salud alguna de las acciones.

- El mismo artículo 20.i indica que el pago de las prestaciones puede realizarse mediante el traspaso de fondos presupuestarios u otras formas de contraprestación, cuestión que es complementada por el artículo $9^{\circ}$ transitorio, que señala la "eventual" entrega de bienes y recursos públicos.

que sean sustituidos por acciones realizadas, mediante el traspaso de los fondos presupuestarios correspondientes u otras formas de contraprestación. Las entidades a que se refiere esta letra quedarán adscritas al Sistema, se sujetarán a sus normas, planes y programas, y serán controladas por el Servicio y el Ministerio de Salud".

66 Artículo $9^{\circ}$ transitorio: "Facúltase al Presidente de la República para que, dentro del plazo de un año y por decreto del Ministerio de Salud, dicte normas generales para la celebración de los convenios entre los servicios de salud y universidades, organismos, sindicatos, asociaciones patronales o de trabajadores y, en general, con toda clase de personas naturales o jurídicas, a fin de que éstos tomen a su cargo, por cuenta de aquellos, algunas de las acciones de salud que les corresponda. En el decreto que se dicte, de acuerdo con lo dispuesto en el inciso anterior, deberá especialmente, entre otras materias, indicarse expresamente la autoridad facultada para celebrar los respectivos convenios, los que siempre requerirán la autorización del Ministerio de Saludi regularse detalladamente la entrega eventual de bienes y recursos públicos y su fiscalización, establecerse el régimen a que quedarán sometidos los funcionarios públicos que pasen a desempeñarse bajo la dependencia de órganos privados, y determinarse las condiciones de suficiencia técnica o de otro tipo con que deberán cumplir las entidades privadas que concurran a su celebración. No obstante lo dispuesto en los incisos precedentes, los convenios suscritos a la fecha de vigencia de esta ley continuarán sometidos, en cuanto corresponda, a la legislación que les era aplicable con anterioridad a dicha fecha de vigencia". 
La regulación de estos convenios se realizó mediante el DFL 36/80. La denominación de convenio sigue la tradición de la regulación sanitaria que permitía al extinto Servicio Nacional de Salud celebrar convenios con entes privados para determinadas prestaciones de seguridad social ${ }^{68}$. También se explica por una falta de un marco normativo relativo a la organización e instituciones administrativas en Chile ${ }^{69}$.

El artículo $2^{\circ}$ del DFL 36/80 establece que se trata de una ejecución de acciones, ya sea por delegación o por mandato, lo que da cuenta de un contrato de prestación de servicios en el sentido del derecho civil ${ }^{70}$. Pero la misma ambigüedad legislativa produce dudas, pues se trata de servicios dirigidos a la ciudadanía y no de labores de apoyo a la Administración, toda vez que los artículos $1^{\circ}$ incisos segundo y tercero y $2^{\circ}$ inciso segundo excluyen expresamente las labores de apoyo a los organismos públicos del ámbito de aplicación de estos convenios.

Conforme al citado artículo $3^{\circ}$ del DL 2.763/79, estos convenios tienen por objeto adscribir a las personas naturales o jurídicas que estén fuera del SNSS. Esta idea es confirmada por los dictámenes n. ${ }^{\circ} 14.232$ y n. ${ }^{\circ} 35.663$ de 1982 de la Contraloría, que excluye los convenios interadministrativos del ámbito de aplicación del DFL 36/80, e indica que estos convenios deben realizarse con organismos distintos (ajenos) de los Servicios de Salud. Aunque las particularidades de la organización Administrativa chilena hicieron que se aplicara a los acuerdos con las universidades públicas (dictámenes n. ${ }^{\circ} 12.819$, n. ${ }^{\circ} 19.950$, n. $^{\circ} 21.637$ y n. $^{\circ} 28.693$ de 1984 ), o con las municipalidades (Dictamen n. ${ }^{\circ} 24.653$ de 1985).

El artículo $7^{\circ}$ del DFL 36/80 ocupa la expresión contratar para referirse a la celebración de estos convenios, lo que permitiría pensar que se trata de un contrato, cuestión que fue refrendada por la jurisprudencia de la Contraloría, que también empleó las expresiones de contratos y convenios como sinónimos en estos acuerdos bilaterales (dictámenes n. ${ }^{\circ} 37.105$ de 1982 y n. ${ }^{\circ} 28.085$ de 1983). Por su parte, el artículo $8^{\circ}$ señala que estos acuerdos no pueden transferir el ejercicio de potestades públicas, como las de control y sanción.

Lo que explicaría este tipo contractual es el objetivo del régimen militar de transformar el sector salud en un mercado sanitario ${ }^{71}$ y de construir un

68 Artículo 76 de la Ley n. ${ }^{\circ}$ 10.383, de 28 de julio de 1952.

69 Gladys Camacho. "Certeza jurídica y el problema de la nulidad de los contratos públicos en Chile", p. 146.

70 Cfr. María Graciela Brantt y Claudia Mejias, "El contrato de servicios como categoría general en el derecho chileno. Su contenido y rasgos distintivos", Ius et Praxis, vol. 24, n. ${ }^{\circ} 3,2018$, p. 585.

71 Dagmar RaczynSKI, "Reformas al sector salud", Colección Estudios CIEPLaN, 1983, n. ${ }^{\circ} 10$ 1983, p. 42. 
sector privado desde el interior el Sistema Público ${ }^{72}$. Al poco tiempo esta idea fue abandonada, y en la reforma al DFL 36/80 realizada por la Ley n. ${ }^{\circ} 18.417$ se indicó que el propósito de estos convenios era que los Servicios de Salud otorgaran asistencia en las localidades en que no cuenten con establecimientos hospitalarios públicos o con especialistas.

Por su parte, la Ley n. ${ }^{\circ} 18.469$ de 1985 fue la que dio facultades al Fonasa para celebrar convenios. Esta modificación estableció las modalidades de atención:

- Modalidad de atención institucional, para beneficiarios que recibían prestaciones de salud por parte de los establecimientos del SNSS y prestadores con convenio del DFL 36/80.

- Modalidad de libre elección, que permite a los beneficiarios de mayores ingresos del Fonasa elegir al prestador que otorgará sus servicios. En este modalidad, profesionales y establecimientos ajenos a los Servicios de Salud podían celebrar un acuerdo, en virtud del cual brindarían prestaciones a usuarios de Fonasa con un arancel prefijado. Una parte es pagada por el beneficiario y otra parte por el Fonasa.

La Ley n. ${ }^{\circ} 18.469$ pretendía asegurar el derecho de libre elección consagrado en la Constitución.

\subsection{LA REFORMA AUGE/GES ${ }^{73}$}

En la década de 1990 no hay intentos de realizar una gran transformación ${ }^{74}$. Los esfuerzos del primer gobierno democrático (1990-1994) en materia de salud se centraron en mejorar la infraestructura del sistema público de salud, mientras que el segundo gobierno de la Concertación impulsa políticas de mejora de la gestión inspiradas en las recomendaciones del Banco Mundial y el Banco Interamericano de Desarrollo, entre otros ${ }^{75}$. Muchas de estas

72 Fabián Moraga Cortés, Thereza Bahía Coelho y Clara Prada Sanabria. "Trayectoria histórica del sistema de salud chileno: Antecedentes para entender el actual esquema de financiamiento", en Convención Internacional de Salud Pública Cuba Salud, 2018, pp. $1-4$.

73 La reforma AUGE/GES fue un paquete legislativo que pretendía asegurar un paquete de prestaciones de salud con financiamiento estatal. Se trata de cuatro leyes, la n. ${ }^{0} 19.895$ de 2003 conocida como "Ley corta de ISAPRE", la n. ${ }^{\circ} 19.937$ de 2004 conocida como "Ley de Autoridad Sanitaria", la n. ${ }^{\circ} 19.966$ de 2004 conocida como "Ley Auge" y la n. ${ }^{\circ} 20.015$ de 2005 conocida como "Ley Larga de ISAPRE".

74 Mario Parada-Lezcano y Fabián Moraga-Cortés, "Crise do seguro seguro saúde no Chile", p. 184.

75 Verónica Figueroa Huencho, "La reforma de la Salud en Chile: implicancias conceptuales y metodológicas para un estudio de caso", en Mauricio Olavarría Gambi 
recomendaciones se recogen en la Ley n. ${ }^{\circ}$ 19.650, también conocida como la Ley de la Compra Pública ${ }^{76}$.

Esta ley modificó completamente el artículo 27 del DL 2.763, cuyo enunciado original señalaba que el Fonasa financiaría las acciones de salud por aportes o pagos directos. El cambio legal permitió que el Fonasa celebrara convenios con entes que no pertenecieran al Sistemas Nacional de Servicios para incorporarlos a la modalidad de atención institucional.

En el Mensaje Presidencial n. ${ }^{\circ}$ 175-336, de 21 de enero de $1998^{[77]}$, el presidente de la República indica que dentro de las facultades que se otorgarán al Fonasa está la de celebrar convenios para:

- Proveer de atención especializada que no tiene el Sistema Nacional de Servicios de Salud.

- Dar cobertura en situaciones de emergencia vital.

- Contar con una herramienta que permitiera a la autoridad sanitaria hacer frente a la interrupción de la provisión de atenciones de salud por motivos ajenos a la disponibilidad de recursos.

Esta última función tenía por objeto que el Gobierno pudiera derivar pacientes al sector privado cuando hubiese paros de los trabajadores sanitarios, cuestión que siempre ha molestado a los gremios de la salud.

Se denominó Ley de la Compra Pública pues establece una priorización en el financiamiento que debe realizar el Fonasa privilegiando a los establecimientos del SNSS y luego a los privados, estableciendo un límite del gasto anual que el Fonasa podía destinar a contratos con el sector privado (10\% del presupuesto destinado a las atenciones de la modalidad de atención institucional). Por supuesto que no estableció un procedimiento para celebrar dichos convenios, aunque dotó de facultades al Fonasa para exigir el cumplimiento por parte de los prestadores privados.

Temporalmente esta ley es anterior a la primera disposición sobre contratación administrativa contenida en el ordenamiento chileno, que fue la Ley n. ${ }^{\circ} 19.653$, que introdujo el actual artículo $9^{\circ}$ de la LOCBGAE, que establece una alusión a la contratación administrativa y que la licitación sería la regla general.

La reforma fue compleja pues enfrentó a diferentes grupos de presión entre sí y con la propuesta inicial del Poder Ejecutivo, lo que se tradujo en

(ed.), ¿Cómo se formulan las políticas públicas en Chile?, t. 2, El Plan Auge y la reforma de la salud, Santiago: Editorial Universitaria, 2012, pp. 36-37.

76 Ulises Nancuante, Andrés Romero y Roberto Sotomayor, Régimen Jurídico de la Salud, Santiago: Thomson Reuters, 2012, p. 212.

77 Biblioteca del Congreso Nacional, Historia de la Ley n.0 19.650: Perfecciona normas del área de la salud. Santiago: Biblioteca del Congreso Nacional, 2018, p. 5. 
complejas negociaciones políticas ${ }^{78}$. Los trabajadores del sector, como burocracia profesional, se resistieron a los cambios ${ }^{79}$ y presionaron para mejorar sus condiciones salariales y de empleo ${ }^{80}$. En el caso de los médicos, se les permitió rebajar sus jornadas de trabajo como empleados públicos y utilizar las dependencias de los centros asistenciales como privados para sus atenciones particulares. Las ISAPRE (instituciones de salud previsional) mantuvieron las facultades de selección de riesgo al poder modificar anualmente los planes de salud, de acuerdo con la edad de los afiliados, cuestión que, si bien fue declarada inconstitucional en 2010, se sigue aplicando.

La Ley n. ${ }^{\circ} 19.937$ sobre autoridad sanitaria estableció que los convenios del DFL 36/80 son los instrumentos por los cuales se incorporaba un particular a una red asistencial. El artículo 17 del DFL 1/2005 $5^{[81]}$ complementa el artículo 3. ${ }^{\circ}$ sobre los convenios para la adscripción de privados al SNSS. El artículo 17 establece la red asistencial de cada servicio regional de salud, entre otros, por establecimientos privados que suscriban el respectivo convenio. Además, el artículo 23 permite a los directores de los servicios regionales de salud celebrar este tipo de convenios, pero no comprar servicios, asunto que reforzaría este carácter colaborativo de los convenios. Esto permitiría pensar que los convenios del DFL 36/80 solo se aplicarían a la adscripción a la respectiva red asistencial del Sistema Nacional de Servicios de Salud.

La descentralización funcional que hizo la Ley n. ${ }^{\circ} 19.937$ respecto de los Servicios de Salud con los hospitales (establecimientos autogestionados en red) podría confirmar esta hipótesis preliminar. Dentro de las atribuciones de los directores de los hospitales está celebrar los convenios del DFL 36/80 (artículo 36.j), comprar servicios de cualquier naturaleza, incluidos los que sean propios del establecimiento (artículo 36.g) y encomendar la ejecución de acciones de apoyo a privados mediante la Ley n. ${ }^{\circ} 18.803$ (artículo 36.h). La ley distingue entre convenios y contratos de compra.

En consecuencia, el convenio tenía un rol de ser el instrumento por el que los privados se incorporan a la red asistencial de un servicio, mientras que

78 Ana Sojo, "Condiciones para el acceso universal a la salud en América Latina: Derechos sociales, protección social y restricciones financieras y políticas", Ciência \& saúde coletiva, vol. $16,{ }^{\circ}{ }^{\circ} 6,2011$, p. 2682.

79 Sobre el rol de los trabajadores en el sector público en las reformas sanitarias, cfr. José RePUlLO LABRADOR, "Sistemas sanitarios y reformas", p. 64.

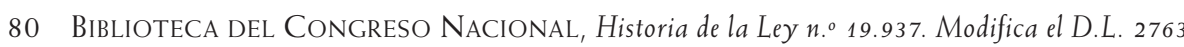
de 1979, con la finalidad de establecer una nueva concepción de la autoridad sanitaria, distintas modalidades de gestión y fortalecer la participación ciudadana, 2018, pp. 27-42.

81 Mediante la reforma AUGE/GES se fusionaron en un solo cuerpo legal, el DFL 1/2005, el DL 2.763/79, con la Ley n. ${ }^{\circ} 18.469$ que regula el ejercicio del derecho constitucional a la protección de la salud y crea un régimen especial de prestaciones, y la Ley n. ${ }^{\circ} 18.933$ sobre ISAPRE. 
los contratos de compra les sirven a los directores de hospitales para dar cumplimiento a la garantía de oportunidad ${ }^{82}$. Ahora bien, los contratos de compra tienen un límite presupuestario, pues los directores solo pueden gastar hasta un $20 \%$ del presupuesto anual para comprar servicios. Por eso es que para sortear el límite presupuestario se utilizó la figura del convenio $^{83}$. Además, el procedimiento para celebrar convenios era bastante laxo, en comparación con las compras de servicios, a las que se les aplicó la Ley de Compras Públicas.

El asunto es complicado pues el informe de auditoría 500 de 2018, establece que la deuda hospitalaria creció entre 2013 y 2016 en 51 \% de promedio por gastos en este subtítulo.

A pesar de que la Reforma AUGE/GES no pretendía que los acuerdos bilaterales se rigieran por la Ley de Compras Públicas, en la práctica el sector salud terminó siendo el principal usuario de los mecanismos de esa ley y que más dinero se transara en el portal electrónico de Chile Compra ${ }^{84}$. La aplicación de esta ley fue una imposición de la Contraloría para mejorar la transparencia de las transacciones.

Los dictámenes n. ${ }^{\circ} 34.883$ de 2004 y n. ${ }^{\circ} 51.729$ de 2005 son los primeros que aplican la Ley de Compras a las contrataciones de servicios por parte de los entes del SNSS. Se trató de servicios de laboratorio, los que están excluidos del ámbito de aplicación del DFL 36/80. El asunto no generó mayor discusión pues estos servicios son considerados como una externalización complementaria desde el punto de vista económico $y$, desde la perspectiva jurídica, son servicios de apoyo a las prestaciones asistenciales.

La ampliación de la aplicación de la Ley de Compras Públicas a servicios asistenciales en favor de los ciudadanos parte en 2006 como producto de dos consultas (más bien peticiones) de la Subsecretaría de Redes Asistenciales. La solicitud era excluir la aplicación de la Ley de Compras Públicas a la celebración de los convenios del DFL 36/80. Mediante los dictámenes n. ${ }^{\circ} 51.081$ de 2006 y n. ${ }^{\circ} 38.109$ de 2007, la Contraloría sostiene que los convenios señalados son un acuerdo de voluntades que genera derechos y deberes para las partes, por lo que se trataría de contratos, y luego hizo una interpretación del artículo $1^{\circ}$ de la Ley de Compras Públicas, y como se entiende la expresión servicios, para aplicar los procedimientos de licitación y adjudicación de la mencionada ley.

En 2009, mediante el dictamen n. ${ }^{\circ} 18.548$, de una forma bastante alambicada, la Contraloría indica que los convenios del DFL 36/80 son contratos pp. $65-68$

83 Ibid., p. 60

84 Ibid., p. 64 
administrativos onerosos y que implican una externalización de tareas, pues tienen por objeto la prestación de servicios a favor de la Administración. Este último punto es discutible, pues los servicios se prestan a favor de las personas.

Es necesario consignar que las facultades externalizadoras de los hospitales han resultado perniciosas, pues inducen a la baja producción de atenciones por parte de los hospitales ${ }^{85}$ y que algunos funcionarios se constituyan como personas jurídicas privadas para vender sus servicios como prestadores privados a los mismos establecimientos en los que se desempeñan ${ }^{86}$.

Esta atribución tenía una lógica externalizadora ya que el legislador consideró que es más barato comprar al sector privado que producir los servicios en el sistema público ${ }^{87}$, y de este modo se podrían controlar los gastos en la gestión de la sanidad, "de manera que estos tengan un costo/efectividad demostrable" 88 .

Esta situación también repercute en la confusión de figuras respecto de si se trata de convenios o contratos. El criterio del dictamen n ${ }^{\circ} 1.557 \mathrm{de}$ 2011 de la Contraloría sostiene que hay que atender al "clasificador presupuestario" (la imputación de gasto a la ley de presupuestos) para distinguir si existe un contrato o convenio. Pareciera ser que la Contraloría indica que los convenios serían aquellos arreglos en que la prestación es realizada por funcionarios de los mismos servicios de salud, como una labor complementaria. En cambio, si las prestaciones son realizadas por particulares ajenos al SNSS se trataría de contratos.

\section{CONVENIOS, CONTRATOS O COMPRAS, ¿CÓMO ENTENDER LOS ACUERDOS BILATERALES?}

La legislación sanitaria chilena indica que los acuerdos bilaterales entre la Administración y particulares pueden ser convenios o contratos. El Fonasa

85 Marcos Vergara, "Propuesta de reformas a los prestadores públicos de servicios médicos en Chile: 'fortaleciendo la opción pública'", Revista Médica de Chile, vol. 143, n. ${ }^{\circ} 2,2015$; COMISIÓN NACIONAL DE Productividad, Informe final: Eficiencia en pabellones y priorización de pacientes para cirugía electiva, pp. 3-4. Recuperado de https://www. comisiondeproductividad.cl/wp-content/uploads/2020/01/INFORME-FINAL-Eficienciaen-Pabellones-y-priorización-de-pacientes-para-cirugía-electiva.pdf [consultado el 12 de enero de 2021].

86 CÁmARA DE Diputados, Informe de la Comisión Investigadora de las adquisiciones de insumos y prestaciones de salud efectuadas por Fonasa a prestadores privados, desde 2012 a la fecha, así como las pérdidas en ejercicios financieros a partir de 2010, y el eventual lucro en de prestadores privados de salud (CEI 35), 2017, pp. 105-106, 184

87 Biblioteca del Congreso NaCional, Historia de la Ley n. ${ }^{\circ}$ 19.937, 2018, p. 12

88 Ibid. 
y los directores de los servicios de salud y de los hospitales celebran convenios, y también estos últimos celebran contratos de compra.

La decisión del Tribunal Constitucional, al sostener que en el ordenamiento jurídico chileno no existen las concesiones de servicios públicos pues no existe el servicio público, es una reacción a la jurisprudencia de la Contraloría, un fallo de la Corte Suprema y a la disidencia del mismo tribunal en el caso que motivó esta sentencia de la Corte.

Surge la interrogante de cómo entender estos acuerdos bilaterales, luego de la decisión del Tribunal Constitucional, que pareciera reconducir a las compras de servicio, desnaturalizando los convenios del DFL 36/80. La decisión del Tribunal Constitucional tiene muchas aristas, una de ellas es que, si los convenios se reducen a contratos de compra, la Administración no podría usarlos para dirigir a los particulares, pues en este caso la carece de poderes de ordenación ${ }^{89}$.

\subsection{UN CONFLICTO DE POSICIONES JURÍDICAS}

La decisión del Tribunal Constitucional es una reacción a los dictámenes n. ${ }^{\circ} 11.781$ y n. $^{\circ} 24.216$ de 2018 de la Contraloría que, en el marco del examen de legalidad del protocolo de objeción de conciencia, sostuvieron que los prestadores privados con convenios del DFL $36 / 80$ no podían esgrimir la objeción de conciencia en caso de que usuarias del SNSS les solicitaran la interrupción del embarazo. La Contraloría utilizó el criterio del dictamen n. ${ }^{\circ} 44.822$ de 2011, en el que se sostuvo en que los convenios del DFL 36/80 existía un traspaso de funciones públicas al prestador. La innovación de los dictámenes de 2018 es que pretendía extender este criterio a todos los convenios celebrados por entes del SNSS, incluido el Fonasa. Esta extensión tiene fundamentos legales, pues de acuerdo con el artículo 111.N del Código Sanitario, los prestadores con convenios con el Fonasa también son parte de la red asistencial, asimilando los convenios del Fondo a los convenios del DFL 36/08.

También, el fallo del Tribunal Constitucional es una reacción a un fallo de la Corte Suprema. En el considerando $8^{\circ}$ de la sentencia Rol 8.337 de 2010, la Corte Suprema calificó la actividad de las ISAPRE como un "servicio público desarrollado por particulares cuyo giro es cubrir las acciones de salud contenidas en la Constitución Política de la República". Por su parte,

89 Francisco Pinilla RodríGuez, "Los fundamentos generales de los poderes de ordenación en el contrato administrativo", en Jorge Bermúdez Soto (ed.), Perspectivas para la modernización del derecho de la contratación administrativa, Valparaíso: Ediciones Universitarias de Valparaíso, 2014, pp. 283-284. 
conociendo del mismo caso, la disidencia del Tribunal Constitucional sostuvo que las ISAPRE eran servicios públicos sui generis (STC Rol Rol 2.337 de 2013).

En consecuencia, en su sentencia de 2019, el Tribunal Constitucional pretendía limitar a la Corte Suprema, que calificó algunas actividades de interés general como servicios públicos. Para eso, sostuvo que la doctrina del servicio público no es aplicable en el derecho chileno. Para responder a la Contraloría sostuvo que, por la inaplicabilidad del servicio público, no puede existir concesiones de servicio público. El problema es que existen más figuras contractuales para la gestión de servicios. Por lo tanto, los convenios solo servirían para que el sistema público busque la provisión de determinados servicios específicos en el sector privado, cuestión que no tiene sustento legal.

La clave está en la concepción que se le da al acuerdo, si se trata de compras, en las que la Administración no puede ejercer potestades de dirección ni tampoco podría discriminar entre aquellos particulares que por razones valóricas no quieren realizar determinas acciones de salud.

\subsection{Convenios o COnTRATOS}

El ordenamiento chileno contempla las figuras de contratos administrativos y convenios interadministrativos en la LOCBGAE. El artículo 38 de la LOCBGAE señala que en aquellos lugares en donde no exista un servicio público, las funciones de este serán asumidas por otro servicio. La noción de servicio público es empleada en este cuerpo legal como "organización administrativa afecta al derecho público" ${ }^{190}$. De acuerdo con el precepto, la figura del convenio solo se aplicaría en los convenios interadministrativos, que materializarían los principios de unidad en la actuación. Hay que tener presente que la LOCBGAE es posterior al DFL 36/80, lo que podría justificar la existencia del convenio como figura autónoma en los sistemas de salud. Refuerza esta que la redacción del DFL 36/80 podría inducir a la conclusión de que se trata de herramientas de colaboración con la Administración. En la práctica, los convenios se usan para distintos fines.

Ahora bien, el artículo 37 de la LOCBGAE señala que se los servicios públicos pueden encomendar la ejecución de acciones, previa autorización legal, mediante contratos.

Desde el punto de vista formal, convenio y contrato son acuerdos de voluntad $^{91}$, por lo que ambos están dentro de la actividad contractual de

90 Gladys Camacho CePeda, Tratado de derecho administrativo, t. IV, La actividad sustancial de la Administración del Estado, Santiago: Thomson Reuters, 2010, p. 269.

91 Augusto CHÁvez Marín, Los convenios de la administración: Entre la gestión pública y la actividad contractual, 2. ${ }^{\text {a }}$ ed., Bogotá: Universidad Nacional del Rosario, 2012, pp. 53-54. 
la Administración. Sin embargo, la doctrina asume que en el contrato hay una contraposición de intereses de las partes ${ }^{92}$, mientras que en el convenio existen fines comunes a ambas partes. Dicho de otro modo, un contrato es una contradicción de causas y fines, mientras que el convenio es una confluencia de intereses ${ }^{93}$. Las resoluciones del Ministerio de Salud ${ }^{94}$ sobre los aranceles de la modalidad de libre elección da una definición que permitiría sostener este criterio. Al respecto, la Resolución Exenta n. ${ }^{\circ} 277$ de 2011 (vigente) define estos acuerdos de la siguiente manera: "El convenio es un acuerdo de voluntades destinado a crear derechos y obligaciones, acuerdo que debe ser de interés y beneficio para ambos contratantes y cuya suscripción no es obligatoria para el Fondo".

De esta definición aparecen dos elementos que permitirían distinguir al convenio del contrato, la confluencia de ambas partes (ya enunciada) y la iniciativa del particular para su celebración, que se explicará en detalle. En relación con la confluencia, se trata de la causa final del convenio que, en el caso de las prestaciones de salud, tanto la Administración como el particular buscan la recuperación o rehabilitación de la salud de una persona ${ }^{95}$. Por su parte, en un contrato de suministro, la Administración obtiene bienes para su funcionamiento mientras que el proveedor busca una ganancia. En último término hay que distinguir qué buscan los acuerdos contractuales, mejorar el mercado o asegurar el derecho a la asistencia sanitaria con atenciones de calidad. La cuestión no es baladí y, muchas veces, ambos objetivos no son complementarios.

En relación con la iniciativa del particular para celebrar el convenio, hay que recordar que los procedimientos de contratación administrativa se inician con un requerimiento de la Administración, una oferta en términos jurídicos que esta realiza al particular ${ }^{96}$. Incluso el diálogo competitivo parte con un "documento descriptivo" de la Administración. Vale decir, en los contratos es la Administración la que toma la iniciativa para celebrar el acuerdo. En

92 José Luis Villar Palasí, citado en ibid., pp. 39-40.

93 Jaime Pintos Santiago, "Los convenios, los encargos de gestión y los contratos públicos", en Jaime Pintos Santiagos y José Antonio Moreno Molina (eds.), Los contratos administrativos y su aplicación: obras, servicios y concesión de obras y servicios, Madrid: El Consultor de los ayuntamientos, 2018, p. 41

94 Se trata de las resoluciones exentas del Ministerio de Salud n. ${ }^{\circ} 134$ de 2006, n. ${ }^{\circ} 148$ de 2007, n. ${ }^{\circ} 253$ de 2008, n. $^{\circ} 49$ de 2009 y n. ${ }^{\circ} 277$ de 2011

95 Ahora bien, este argumento presenta la dificultad que, probablemente, no será resuelto por el derecho en relación con el fin perseguido por particulares, ya sean personas naturales o jurídicas, respecto del lucro, pues los artículos $2^{\circ}$ y $3^{\circ}$ del DFL $1 / 2005$ no establecen una diferencia al respecto. En definitiva, es una cuestión político-ideológica definir qué busca el particular cuando brinda prestaciones sanitarias.

96 José LuIs MeILÁN GIL, "El contrato público determinado por el interés general", Revista de la Facultad de Derecho de México, vol. LXVIII, n. ${ }^{\circ} 271,2018$, p. 681 
los convenios, al menos los casos del sector sanitario chileno, son los particulares los que solicitan el vínculo.

En efecto, el artículo $3^{\circ}$ del DFL 1/2005 señala que los particulares gozarán de libre iniciativa para adscribirse al Sistema, suscribiendo los convenios que correspondan. Asimismo, el artículo 143 del DFL 1/2005 establece que los profesionales y establecimientos que decidan otorgar prestaciones en la modalidad de libre elección deberán suscribir el convenio, y tal como se indica en la mencionada resolución exenta $n .{ }^{\circ} 277$, la solicitud de celebrar el convenio no es obligatoria para el Fonasa.

Ahora bien, el derecho de la contratación pública tiene por objeto garantizar el buen funcionamiento del mercado y asegurar la competencia entre los operadores económicos ${ }^{97}$. La Ley de Compras Públicas contempla un objetivo similar en el artículo 30.g, que indica que la Dirección de Compras debe promover la máxima competencia posible e incorporar en las licitaciones a la mayor de oferentes. La Ley de Compras tiene por objeto garantizar el funcionamiento del mercado.

\subsection{Los problemas de la ley de Compras Públicas}

La figura del contrato de compras de servicios genera bastante incomodidad en el ámbito de la gestión de la Sanidad Pública. Si la gestión sanitaria puede realizarse comprando prestaciones, surge la duda respecto de qué es lo que busca la sanidad, si garantizar el buen funcionamiento del mercado sanitario o garantizar un derecho fundamental. Precisamente es esta concepción externalizadora la que produce problemas en el financiamiento. El informe de auditoría 500 de 2018 de la Contraloría establece que la deuda hospitalaria creció entre 2013 y 2016 en un $51 \%$ de promedio por compras de servicio. Los hospitales se endeudan para comprar servicios que no producen, y compran estos servicios a sus mismos funcionarios, que venden servicios como prestadores privados. El crecimiento sostenido de la deuda hospitalaria es una paradoja si se considera que entre 2006 y 2019 se ha triplicado el gasto público en sanidad ${ }^{98}$.

La solución de los gobiernos de 2006 en adelante pivota entre aumentar los recursos en remuneraciones de personal o los recursos para comprar atenciones a prestadores privados. Pero falta una política clara para superar estas carencias en la producción de atenciones por parte del sector público.

97 Silvia Díez SaStre, "Contratación pública socialmente responsable", en Javier Guillén Caramés y María Hernando Rydings (dirs.), Contratación, competencia y sostenibilidad: Últimas aportaciones desde el derecho administrativo, Pamplona: Thomson Reuters, 2017, p. 267.

98 Sebastián Flores DíAZ, "La participación privada en la gestión de la salud pública", p. 69. 
Desde el punto de vista jurídico, la compra de prestaciones de servicios no es una figura que permita explicar estas prestaciones en beneficio de las personas. La parca redacción del artículo $1^{\circ}$ de la Ley de Compras Públicas da a entender que los servicios son para el apoyo de las labores administrativas (como señalaba el proyecto de ley). En la prestación de servicios de salud hay un ejercicio de actividades públicas en beneficio de la sociedad.

En la práctica, la Ley de Compras se aplica a todos los acuerdos entre entes del SNSS y particulares, por disposición de la Contraloría ${ }^{99}$. Aunque es discutible la interpretación que cualquier transferencia de recursos del sector público a particulares para realizar una actuación conjunta sea una compra de suministros.

El problema de "comprar" está en la posición que asume la Administración y también en el rol que asumen los particulares. La compra de servicios reconduciría a un mercado en el que la Administración juega un rol de comprador (pero no de dirección), mientras que los particulares se transforman en competidores del sector público. Este es el problema no resuelto en la prestación de servicios sanitarios, con el añadido de que no es tan claro que solo la competencia entre el sector público y los particulares garantice de por sí una mejor calidad de las prestaciones médicas.

Las características puntuales de esta forma de gestión bien podrían encuadrarse en la concesión de servicios públicos o en el reciente contrato de servicios a las personas que contemplan la Directiva 2014/24/UE y la Ley 9 de 2017, de Contratos del Sector Público de España.

\section{CONCLUSIONES}

La gestión de la salud pública mediante compras de prestaciones de servicios abre la posibilidad para analizar y cuestionar tanto el derecho de la contratación pública que cada día cobra más adeptos, como la regulación del empleo público (¿es necesario continuar con estatutos funcionarios cuando se trata de administraciones que no ejercen potestades de imperio?) sin vulnerar los derechos laborales, pero cuidando los recursos públicos y la profesionalización del Estado. También controvierte el impacto de las reformas impulsadas desde la década de 1990 y los remedios de los gobiernos progresistas a esas reformas. La mercantilización de la gestión pública se combatió con mayor empleo público y parece ser que la ciudadanía no está contenta con el remedio ni con la enfermedad.

La diferencia entre el contrato y el convenio tiene diferentes alcances. En los convenios de la sanidad se pretende articular una red asistencial. En 
los contratos de compra se busca la provisión de suministro. Vale la pena reflexionar si es necesario mantener la distinción y tomar una opción legislativa para regularla, o quedarse con las compras públicas y todos los problemas que han generado.

Pareciera ser que no se trata de seguir ampliando la aplicación de la Ley de Compras Públicas, sino que mejorar la técnica regulatoria de los convenios, sus procedimientos de celebración y los mecanismos para asegurar la probidad, la transparencia $y$, eventuales, las sanciones para quienes las incumplan. Al menos, el Fonasa tiene facultades de sanción en los convenios que celebra, cuestión que no es explícita en los convenios celebrados por prestadores públicos. Durante la pandemia quedó de manifiesto que la Ley de Compras Públicas es ineficaz para seleccionar a los mejores contratantes en el sector salud, y también que es muy sencillo incumplirla sin tener consecuencias, o si las hay, solo se ven reflejadas en una demora por el pago de los servicios. Esta situación es un desafío, al menos para la doctrina iusadministrativista chilena, que sigue discutiendo temas importantes como las eventuales modernizaciones o reformas a la Administración, sin analizar cómo se han implementado los cambios legales ya realizados. Las reformas inspiradas en la nueva gestión pública produjeron una avalancha de juristas que pretendían ser economistas y pontificar, en lugar de analizar las reformas administrativas. Abundan estudios que, inspirados en el Law and economics o en la regulación anglosajona, pretenden importar sin mayor reflexión sobre su aplicación en contextos latinoamericanos. Tal vez haya que empezar a buscar categorías que propendan a la solidaridad en sociedades inequitativas. En ese aspecto, las nuevas tendencias del derecho administrativo pueden ofrecer buenas opciones para este propósito, pero primero es necesario entender que ha ocurrido con la Administración pública después de tanta reforma.

\section{BIBLIOGRAFÍA}

\section{DOCTRINA}

Albuquerque, Maria, Heloísa Morais y LuCi Lima. "Contratualização em saúde: arena de disputa entre interesses públicos e privados". Ciência \& saúde coletiva", vol. 20, n. ${ }^{\circ} 6,2015$.

BAnCo Mundial. "El financiamiento de los servicios de salud en los países en desarrollo. Una agenda para la reforma". Boletín de la Oficina Sanitaria Panamericana, vol. 103, n. $^{\circ} 6,1987$.

BANCO MUNDIAL. Informe sobre el desarrollo mundial 1993. Invertir en salud. Washington: Banco Mundial, 1993. 
Barba Solano, Carlos. "Liberalismo y universalismo: 25 años de reformas sociales en los regímenes de bienestar de América Latina". En Carmen Midaglia, Gerardo Ordóñez, y Enrique Valencia, (eds.). Políticas sociales en América Latina en los inicios del siglo XXI. Innovaciones, inercias y retrocesos, Buenos Aires: Clacso, 2018.

Barra Gallardo, Nancy, y Gabriel Celis DanZinger. Contratación administrativa bajo la ley de compras, $4{ }^{a}$ ed. Santiago: Thomson Reuters, 2015

Bell, JoHn S. "Comparative Administrative Law". En Mathias Reimann y Reinhard Zimmermann (eds.), The Oxford Handbook of comparative law. Londres: Oxford University Press, 2019.

Benatar, Solomon, David Sanders y Stephen Gill. "The Global Politics of Healthcare Reform". En Colin Mcinnes, Kelley Lee y Jeremy Youde (eds.), The Oxford Handbook of Global Health Politics. Oxford: Oxford University Press, 2018.

Bestard Perello, Juan. "Servicio público versus aseguramiento público. Apuntes ante retos pendientes (II)". Actualidad del Derecho Sanitario, n. ${ }^{\circ}$ 272, 2019.

Biblioteca del Congreso Nacional. Historia de la Ley n. 19.650: Perfecciona normas del área de la salud. Santiago: Biblioteca del Congreso Nacional, 2018.

Biblioteca del Congreso Nacional. Historia de la Ley n. 19.937. Modifica el D.L. 2763 de 1979, con la finalidad de establecer una nueva concepción de la autoridad sanitaria, distintas modalidades de gestión y fortalecer la participación ciudadana. Santiago: Biblioteca del Congreso Nacional, 2018.

Biblioteca del Congreso Nacional. Historia del Decreto Ley n.o 2.763, de 1979. Santiago: Biblioteca del Congreso Nacional, 1980.

Biblioteca del Congreso NaCiOnal. Mensaje presidencial. 11 septiembre 1979-11 septiembre 1980. Santiago: Biblioteca del Congreso Nacional, 1980.

Blanquer CRIADO, DAVID. La concesión de servicio público. Valencia: Tirant Lo Blanch, 2012.

Brantt, María Graciela, y Claudia Mejias. "El contrato de servicios como categoría general en el derecho chileno. Su contenido y rasgos distintivos". Ius et Praxis, vol. 24, n. ${ }^{\circ} 3,2018$.

Camacho Cepeda, Gladys. "Certeza jurídica y el problema de la nulidad de los contratos públicos en Chile". Revista digital de Derecho Administrativo, n. ${ }^{\circ}$ 25, 2020.

Camacho Cepeda, Gladys. "Chile en la contratación pública en América Latina". En José Luis Benavides y Pablo Moreno Cruz (eds.), La contratación pública en América Latina. Bogotá: Universidad Externado de Colombia, 2017. 
Camacho CePeda, Gladys. Tratado de derecho administrativo, t. IV, La actividad sustancial de la Administración del Estado. Santiago: Thomson Reuters, 2010.

CÁmARA DE Diputados. Informe de la Comisión Investigadora de las adquisiciones de insumos y prestaciones de salud efectuadas por Fonasa a prestadores privados, desde 2012 a la fecha, así como las pérdidas en ejercicios financieros a partir de 2010, y el eventual lucro en de prestadores privados de salud (CEI 35), 2017.

Cantero Martínez, Josefa. "La incidencia del fenómeno de la externalización en la Administración General del Estado. ¿Existe algún límite?. Documentación Administrativa, n. ${ }^{\circ}$ 286-287, 2010.

CÁrdenas Poveda, Margarita. "La armonización del derecho administrativo en la globalización". En John Tito Añamuro (dir.), Derecho internacional privado. Un estudio de tratados, proyectos de unificación y leyes modelos. Barranquilla: Universidad del Norte, 2020.

Cassagne, Juan Carlos. "Actuales desafíos y clásicos dilemas de la contratación pública". En José Carlos Laguna de Paz, Íñigo Sanz Rubiales e Isabel de los Mozos Touya, (coords.), Derecho administrativo e integración europea. Estudios en bomenaje al profesor José Luis Martínez López-Muñiz. Madrid: Reus, 2017.

Chávez Marín, AuguSto. Los convenios de la Administración: Entre la gestión pública y la actividad contractual, 2. ${ }^{a}$ ed. Bogotá: Universidad Nacional del Rosario, 2012.

Comisión NACIONAL de Productividad. Informe final: Eficiencia en pabellones y priorización de pacientes para cirugía electiva. Recuperado de https://www.comisiondeproductividad.cl/wp-content/uploads/2020/01/INFORME-FINAL-Eficienciaen-Pabellones-y-priorización-de-pacientes-para-cirugía-electiva.pdf [consultado el 12 de enero de 2021].

CONTRAloría General De la RePúBlica. Informe consolidado de auditoría al endeudamiento bospitalario, n. ${ }^{\circ} 500,2018$.

Cortez, Nathan. "Globalization". En Glenn Cohen, Allison Hoffman, William M. Sage y Kathleen G. Sebelius (eds.), The Oxford Handbook of U.S. Health Law. Oxford: Oxford University Press, 2015.

Darnaculleta i Gardella, MerCÉ. Derecho administrativo y autorregulación: La autorregulación regulada, tesis doctoral. Girona: Universitat de Girona, 2002.

Díez Sastre, Silvia. "Contratación pública socialmente responsable". En Javier Guillén Caramés y María Hernando Rydings (dirs.), Contratación, competencia y sostenibilidad: Últimas aportaciones desde el derecho administrativo. Pamplona: Thomson Reuters, 2017. 
Esteve Pardo, José. "La deconstrucción de las fórmulas de intervención administrativa. De la aplicación de la Ley a la contractualización". Revista Vasca de Administración Pública, n. ${ }^{\circ}$ 99, 2014.

Figueroa Huencho, Verónica. "La reforma de la salud en Chile: Implicancias conceptuales y metodológicas para un estudio de caso". En Mauricio Olavarría Gambi (ed.), ¿Cómo se formulan las políticas públicas en Chile?, t. 2, El Plan Auge y la reforma de la salud. Santiago: Editorial Universitaria, 2012.

Filippon, Jonathan, Ligia Giovanella, Mariana Konder y Allyson Pollock. "A 'liberalização' do Serviço Nacional de Saúde da Inglaterra: trajetória e riscos para o direito à saúde". Cadernos de Saúde Pública, vol. 32, n. ${ }^{\circ}$ 8, 2016.

Flores Díaz, SEBAStián. "La participación privada en la gestión de la salud pública". Revista de Gestión Pública, vol. 9, n. ${ }^{\circ}$ 1, 2021.

FOnT I LlOVET, TOMÁs. "Organización y gestión de los servicios de salud: El impacto del derecho de la Unión Europea". En Vera Parisio, Vincent Aguado y Cudola y Belén Noguera de la Muela (eds.), Servicios de interés general colaboración público-privada y sectores específicos. Valencia: Tirant Lo Blanch, 2016.

Franco-Giraldo, Álvaro. "Sistemas de salud en condiciones de mercado: las reformas del último cuarto de siglo". Revista Facultad Nacional de Salud Pública, vol. 32, n. $^{\circ} 1,2014$.

Gorelli HernándeZ, JuAN. "La externalización de los servicios sanitarios públicos y las posibles consecuencias laborales". En Federico Castillo Blanco (dir.), Público y privado en la gestión de los servicios públicos: Reestructuración, externalización y reversión a la Administración. Madrid: INAP, 2019.

Gostin, LaWrence, y Phil Fennell. "Health: The Health Care System, Therapeutic Relationships, and Public Health". En Mark Tushnet y Peter Cane (eds.), The Oxford Handbook of Legal Studies. Oxford: Oxford University Press, 2005.

Maceira, DANiEl. Mecanismos de pago a prestadores en el sistema de salud: incentivos, resultados e impacto organizacional en países en desarrollo. Estudios Mayores de Investigación Aplicada 2, Documento de Trabajo 2. Bethesda: Partnerships for Health Reform Project, Abt Associates Inc., 1998.

MEILÁN GIL, José LUIS. "El contrato público determinado por el interés general". Revista de la Facultad de Derecho de México, t. LXVIII, n. ${ }^{\circ}$ 271, 2018.

Meneu, Ricard, y Rosa URbanos. "La colaboración público-privada en sanidad. Hasta dónde y cómo delimitar sus fronteras". Cuadernos Económicos del ICE, n. ${ }^{\circ} 96$, 2018 . 
Moraga Cortés, Fabián, Thereza Bahía Coelho y Clara Prada Sanabria. "Trayectoria histórica del sistema de salud chileno: Antecedentes para entender el actual esquema de financiamiento". Convención Internacional de Salud Pública Cuba Salud 2018. Recuperado de http://convencionsalud2018.sld.cu/index.php/connvencionsalud/2018/paper/view/787/180 [consultado el 12 de enero de 2021].

Morales-Casetti, Marjorie, Marco Bustos-Gutiérrez y Jenny Cerda-Bustos. "Efectos de la nueva gestión pública en el desempeño: Análisis de los hospitales públicos chilenos". Revista de Salud Pública, vol. 21, n. ${ }^{\circ} 3,2019$.

Muñoz Machado, Santiago. Diccionario panbispánico del español jurídico, Madrid: Santillana, 2017.

Muñoz Machado, SAnTiago. Tratado de derecho administrativo y derecho público general. XIII contratos del sector público. Madrid: Agencia Estatal Boletín Oficial del Estado, 2018.

NAncuante, Ulises, Andrés ROMERO y ROBERTO SOTOMAyOr. Régimen jurídico de la salud. Santiago: Thomson Reuters, 2012,

Organización Mundial De la SAlud. 109. a reunión del Consejo Ejecutivo. Función de los arreglos contractuales en la mejora del desempeño de los sistemas de salud. Ginebra: Organización Mundial de la Salud, 2001.

OrganizaCión MUNDiAL DE LA SALUD. Informe sobre la salud en el mundo 2000. Mejorando el desempeño de los sistemas de salud. Ginebra: Organización Mundial de la Salud, 2000.

Parada-lezcano, Mario y Fabián Moraga-Cortés. "Crise do seguro saúde no Chile: doença crônica socialmente transmissível". Tempus, actas de saúde colet, Brasília, vol. 1, n. ${ }^{\circ}$ 2, 2019.

PIÑERA ECHEÑIQUE, JOSÉ. Informe económico. 1976-1977. Santiago: edición propia, 1977.

Pinilla Rodríguez, Francisco. "Los fundamentos generales de los poderes de ordenación en el contrato administrativo". en Jorge Bermúdez Soto (ed.), Perspectivas para la modernización del derecho de la contratación administrativa. Valparaíso: Ediciones Universitarias de Valparaíso, 2014.

Pintos Santiago, Jaime. "Los convenios, los encargos de gestión y los contratos públicos". En Jaime Pintos Santiagos y José Antonio Moreno Molina (eds.), Los contratos administrativos y su aplicación: obras, servicios y concesión de obras y servicios. Madrid: El Consultor de los Ayuntamientos, 2018.

PLISCOFF-VARAS, CRISTIÁN. "Implementando la nueva gestión pública: problemas y desafíos a la ética pública. El caso chileno". Convergencia, vol. 24, n. ${ }^{\circ}$ 73, 2017. 
RaCZYNSKI, DaGmar. "Reformas al sector salud". Colección Estudios CIEPLAN, n. ${ }^{\text {10, }}$ 1983.

REPULLO LABRADOR, JOSÉ. "Sistemas sanitarios y reformas: Dimensiones, escenarios y patrones". En José Repullo Labrador (dir.), Gestión sanitaria para la calidad y la excelencia. Madrid: Díaz de Santos, 2014.

RODRíGUEZ, MARISOL. "El sector público y el sector privado de la sanidad: ¿Estabilidad o cambio?". Gaceta Sanitaria, vol. 33, n. ${ }^{\text {9 }} 2019$.

SCHMIDT-ASSMANN, EBerhard. "Contractualización del derecho administrativo". En Alberto Montaña Plata y Jorge Rincón Córdoba. Contratos públicos: Problemas, perspectivas y prospectivas. Bogotá: Universidad Externado de Colombia, 2017.

Sevilla, Jordi, E Ignacio Riesgo. Qué está pasando con tu sanidad. Barcelona: Profit Editorial, 2018.

Sojo, AnA. "Condiciones para el acceso universal a la salud en América Latina: derechos sociales, protección social y restricciones financieras y políticas". Ciência \& saúde coletiva, vol. 16, n. ${ }^{\circ} 6,2011$.

Supiot, Alain. Homo juridicus. Ensayo sobre la función antropológica del Derecho, 2. a ed. Buenos Aires: Siglo Veintiuno Editores, 2012.

Valdivieso, Vicente, y Joaquín Montero. "El Plan Auge: 2005 a 2009". Revista Médica de Chile, vol. 138, n. ${ }^{\circ} 8,2010$.

Velasco Caballero, Francisco. "Ideas ordenadoras del derecho administrativo". En Marcos Vaquer Caballería, Ángel Manuel Moreno Molina y Antonio Descalzo González (coords.), Estudios de derecho público en bomenaje a Luciano Parejo Alfonso. Valencia: Tirant Lo Blach, 2019.

Velasco Caballero, Francisco. "Reformas de la Administración pública: Fenomenología, vectores de cambio y función directiva del derecho administrativo". Anuario de la Facultad de Derecho de la Universidad Autónoma de Madrid, n. ${ }^{2}$ 23, 2019.

Velasco Caballero, Francisco. Administraciones públicas y derechos administrativos. Madrid: Marcial Pons, 2020.

Vergara, Marcos, y María Soledad Martínez. "Financiamiento del sistema de salud chileno". Salud Pública de México, vol. 48, n. ${ }^{\circ}$ 6, 2006.

Vergara, Marcos. "Propuesta de reformas a los prestadores públicos de servicios médicos en Chile: 'Fortaleciendo la opción pública'". Revista Médica de Chile, vol. 143, n. ${ }^{\circ} 2,2015$. 
Vergara, Marcos. "Reforma de los mecanismos de pago del sector público de la salud en Chile", 2020. Recuperado de https://www.uchile.cl/noticias/144204/ reforma-de-los-mecanismos-de-pago-del-sector-publico-de-la-salud [consultado el 12 de enero de 2021].

VIDA FERnÁNDEZ, José. "Los servicios públicos de solidaridad en la Unión Europea: Los límites del mercado único y la competencia en los servicios de interés general". En Tomás de la Quadra-Salcedo (ed.), Los servicios públicos tras la crisis económica, en especial la asistencia sanitaria en la Unión Europea. Valencia: Tirant Lo Blanch, 2017.

\section{JURISPRUDENCIA}

Corte Suprema de Justicia, sentencia de 28 de enero de 2011, Rol 8.837-2010.

Tribunal Constitucional, sentencia de $1{ }^{\circ}$ de octubre de 2013, Rol 2.337-12-INA.

Tribunal Constitucional, sentencia de 18 de enero de 2019, Roles 5.572-18-CDS y 5.650-18-CDS (acumuladas).

Contraloría General de la República, Dictamen de 30 de abril de 1982, n. ${ }^{\circ} 14.232$.

Contraloría General de la República, Dictamen de 19 de noviembre de 1982, n. ${ }^{\circ} 35.663$.

Contraloría General de la República, Dictamen de 6 de diciembre de 1982, n. ${ }^{\circ} 37.105$.

Contraloría General de la República, Dictamen de 12 de diciembre de 1983, n. ${ }^{\circ} 28.085$.

Contraloría General de la República, Dictamen de 11 de mayo de 1984, n. ${ }^{\circ} 12.819$.

Contraloría General de la República, Dictamen de 24 de julio de 1984, n. ${ }^{\circ} 19.950$.

Contraloría General de la República, Dictamen de 10 de agosto de 1984, n. ${ }^{\circ} 21.637$.

Contraloría General de la República. Dictamen de 30 de octubre de 1984, n. ${ }^{\circ} 28.6936$.

Contraloría General de la República, Dictamen de 25 de octubre de 1985, n. ${ }^{\circ} 24.653$.

Contraloría General de la República, Dictamen de 14 de julio de 2004, n. ${ }^{\circ}$ 53.449.

Contraloría General de la República, Dictamen de 2 de noviembre de 2005, n. ${ }^{\circ} 51.729$. 
Contraloría General de la República, Dictamen de 27 de octubre de 2006, n. ${ }^{\circ} 51.081$.

Contraloría General de la República, Dictamen de 22 de agosto de 2006, n. ${ }^{\circ} 38.109$

Contraloría General de la República, Dictamen de 2 de octubre de 2008, n. ${ }^{\circ} 45.922$.

Contraloría General de la República, Dictamen de 18 de diciembre 2008, n. ${ }^{\circ} 59.990$.

Contraloría General de la República, Dictamen de 31 de diciembre de 2008, n. ${ }^{\circ} 62.518$.

Contraloría General de la República, Dictamen de 13 de abril de 2009, n. ${ }^{\circ} 18.548$.

Contraloría General de la República, Dictamen de 11 de enero de 2011, n. ${ }^{\circ} 1.557$.

Contraloría General de la República, Dictamen de 15 de julio de 2011, n. ${ }^{\circ} 44.822$.

Contraloría General de la República, Dictamen de 9 de mayo de 2018, n. ${ }^{\circ} 11.781$.

Contraloría General de la República, Dictamen de 27 de septiembre de 2018, n. ${ }^{\circ} 24.216$. 